\title{
The impact of lithium nitrate on the physical and mechanical properties of Portland cement
}

\author{
Justyna Zapała-Sławeta ${ }^{1, *}$, Zdzisława Owsiak $^{1}$ \\ ${ }^{1}$ Kielce University of Technology, al. Tysiąclecia Państwa Polskiego 7, 25-314 Kielce, Poland
}

\begin{abstract}
The effectiveness of lithium nitrate as a chemical additive which reduces the negative effects of alkali aggregate reaction was subject to research by scientists in many centres around the world. The literature data on the impact of lithium nitrate on the physical and mechanical properties of cements are rare. Without a precise definition of the impact of lithium nitrate on the cement properties, it is extremely hard to determine its real advantages in practical usage. In this paper, studies were undertaken to assess the impact of $\mathrm{LiNO}_{3}$ on the properties of pastes and mortars with Portland cement. The rate of hydration of the cement with lithium additive was examined by isothermal calorimetry, measurements of setting time and phase composition of cement pastes in the initial stages of hydration. The influence of the admixture on the compressive strength development of mortars after 2, 7 and 28 days of hardening was also researched. Results indicate that lithium nitrate accelerates the early hydration of Portland cement, affecting the precipitation of hydration products. The compressive strength of mortars with lithium admixture decrease after 28 days, although 2 an 7-day strength were greater than the control mortars.
\end{abstract}

\section{Introduction}

The problem of the alkali aggregate reaction was first noticed in the United States of America in the 1940s, when Stanton provided evidence for the existence of internal corrosion processes, leading to concrete expansion and cracking [1]. Detailed analyses of the alkali reactive aggregates reaction, conducted by many researchers worldwide indicated that the chemical interaction in concrete may occur between alkali and different types of aggregates. In 1957 Swenson demonstrated the occurrence of a reaction between alkali and carbonate aggregate, indicating that it is a different type of a reaction between aggregate and sodium and potassium hydroxides than the one discovered by Stanton [2]. The effects of the alkali aggregate reaction were observed in elements such as concrete sidewalks, concrete pavements, bridges, dams and other structures exposed to humidity over an extended period of time [3].

The negative effects of alkali-silica reaction in concrete can be reduce by some supplementary cementing materials which leads to reduction the amount of alkalis available for reaction with aggregate [4-7]. Another way of diminishing deleterious expansion due to

\footnotetext{
*Corresponding author: jzapala@tu.kielce.pl
} 
alkali aggregate reaction is the addition of lithium nitrate to the concrete mix, which was first proposed by McCoy and Cadwell in 1960s [8]. As a result of the research programmes conducted later on by the U.S Department of Transportation, Federal Highway Administration Research and Technology, it has been proven that lithium nitrate was used as a compound efficiently limiting internal corrosion of the concrete in airport pavements in Atlanta as well as bridges and highways among others in Mexico, Texas and Pennsylvania [9].

Choosing the right amount of lithium nitrate, which would limit concrete expansion caused by the alkali aggregate reaction, depends on the amount of the alkali in the cement as well as the type, the amount and the location of reactive minerals in the aggregate $[10,11]$. Lithium nitrate is introduced into the concrete mix together with mixing water and the amount of the lithium ions introduced corresponds to the molar ratio of $\mathrm{Li}$ to $[\mathrm{Na}+\mathrm{K}]$. The optimum amount of lithium ions, expressed by means of the molar ratio of the total amount of alkali in the cement oscillates around the value of $0.72-1.0[12,13]$. For economic reasons, the evaluation of the efficacy of the use of lithium nitrate in the smallest possible amounts is pivotal. However, the possibility to use greater amounts of lithium nitrate should be considered for the sake of additional or a more long-lasting protection of concrete exposed to internal corrosion. Apart from determining the efficiency of $\mathrm{LiNO}_{3}$ with regards to limiting the linear expansion of concrete, it is crucial to research the effect adding the lithium additive has on the physical and mechanical properties of cement. The research concerning the impact of lithium salts on the properties of the cement pastes and mortars was scarce. The results of these analyses are inconclusive. Some researchers indicate among others that the cement strength decreases and the setting time is reduced as a result of a reaction with the lithium compound, whereas others show no record of a significant effect $\mathrm{LiNO}_{3}$ might have on the above mentioned properties [14].

In this paper, studies were undertaken to assess the impact of lithium nitrate on the properties of Portland cement pastes and mortars. What was evaluated was the effect of $\mathrm{LiNO}_{3}$ on i) cement hydration, by means of determining the changes in the kinetics of reaction ii) the strength of the Portland cement mortars.

\section{Materials and methods}

In order to efficiently prevent the alkali aggregate reaction using lithium nitrate it is crucial to add the correct amount of this salt. The molar ratio of the lithium ions to the contents of alkali in the cement, which amounts to 0.74 and is the so called recommended dosage, is considered to be sufficient in most cases. In this paper, the $\mathrm{Li} /[\mathrm{Na}+\mathrm{K}]$ molar ratio, amounting to 0.74 , was assumed to be the $100 \%$ of the $\mathrm{LiNO}_{3}$ dosage. This ratio may increase for aggregates with greater reactivity. Due to the above, $100 \%$ and $200 \%$ of the recommended dosage of the lithium nitrate was used during the tests. For comparison purposes, tests were executed on cement without the lithium additive. The tests were executed using CEM I 42,5R Portland cement pastes and mortars, the composition of which is presented in table 1 .

Table 1. The chemical composition of the CEM I 42,5R [\%].

\begin{tabular}{|l|l|l|l|l|l|l|l|l|l|l|}
\hline Material & $\mathrm{SiO}_{2}$ & $\mathrm{Al}_{2} \mathrm{O}_{3}$ & $\mathrm{Fe}_{2} \mathrm{O}_{3}$ & $\mathrm{CaO}$ & $\mathrm{MgO}$ & $\mathrm{SO}_{3}$ & $\mathrm{~K}_{2} \mathrm{O}$ & $\mathrm{Na}_{2} \mathrm{O}$ & $\mathrm{TiO}_{2}$ & $\mathrm{Na}_{2} \mathrm{O}_{\mathrm{e}}$ \\
\hline Cement & 18.47 & 5.40 & 2.80 & 60.77 & 1.42 & 3.34 & 0.93 & 0.18 & 0.45 & 0.79 \\
\hline
\end{tabular}

The heat of hydration of the cement without the lithium additive as well as of the cement containing $100 \%$ and $200 \%$ of the $\mathrm{LiNO}_{3}$ dosage was measured using the BT 2.15 differential scanning calorimeter, while working in semi adiabatic conditions. The samples for the calorimetric tests were prepared in the form of pastes with the w/c coefficient of 0.5 and an 
appropriate amount of $\mathrm{LiNO}_{3}$. At the same time, cement phase compositions were being determined, using the X-ray analysis (XRD). What was determined was the effect of the lithium additive on the setting times of cement pastes in the Vicat needle, in accordance with the method described in the PN-EN 196-3:2006 standard [15]. The compressive strength was determined using mortar beams measuring $4 \times 4 \times 16 \mathrm{~cm}$, while the w/c ratio in the samples without the lithium additive and with the $\mathrm{LiNO}_{3}$ was constant and equal to 0.46 . The compressive strength of the mortars was determined after 2, 7 and 28 days of hardening.

\section{Results}

\subsection{Heat of hydration}

The calorimetry test results of the cement pastes being analysed are presented in Figure 1 in the form of a heat release rate versus time curve.

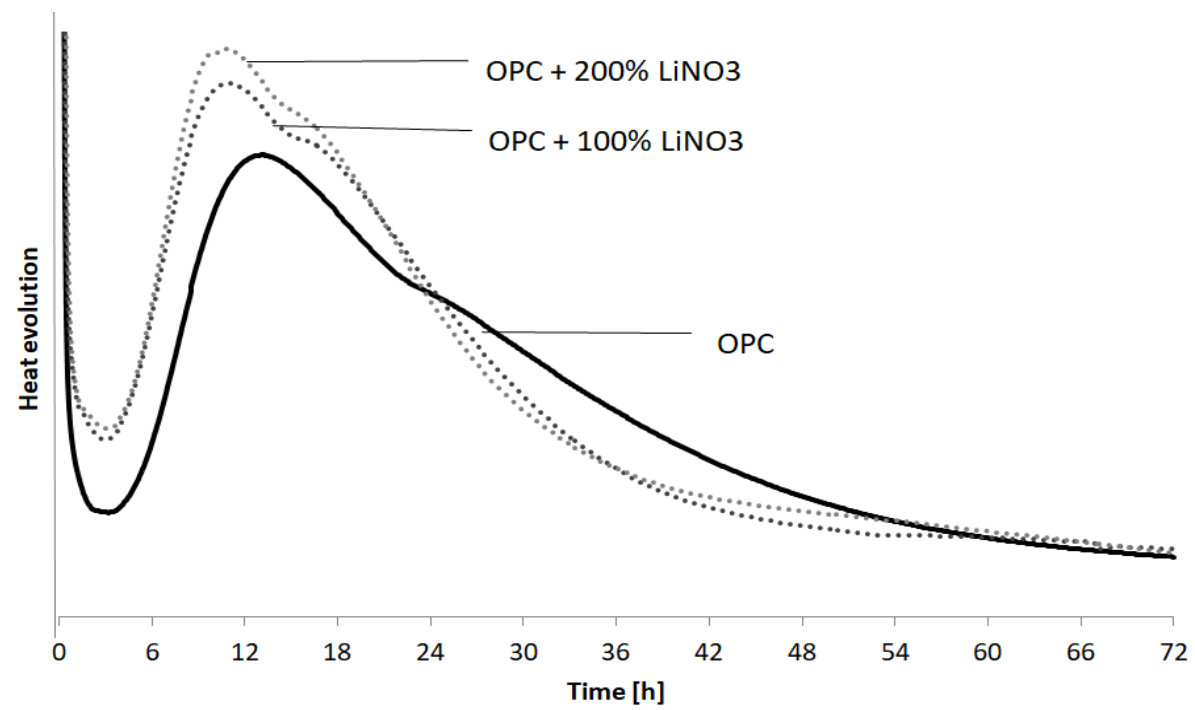

Fig. 1. The calorimetric curves of Portland cement with lithium additive

When comparing the course of the calorimetric curves, an increase in the heat release rate was noticed in the induction period in the pastes with the lithium admixture. It may be stated, that in $\mathrm{LiNO}_{3}$ pastes the induction period dissipates and the cement paste does not regain its initial temperature. The analysis of a further fragment of the curve, which shows the so-called reaction acceleration effect connected to the quick crystallization of the products is moved in time towards the beginning of hydration. As it is shown in the subject matter literature, a greater number of alkali leads to an increase in the reactivity of the $\mathrm{C}_{3} \mathrm{~S}$ and $\mathrm{C}_{3} \mathrm{~A}$ phase [3]. The energy transfer effect in the cement pastes with $\mathrm{LiNO}_{3}$ indicating the tricalcium silicate hydration phase is moved in time by approximately $3 \mathrm{~h}$. There were greater differences noted in the process of the hydration of $\mathrm{C}_{3} \mathrm{~A}$ occurring with $\mathrm{LiNO}_{3}$ present. The energy transfer effect connected with the hydration of $\mathrm{C}_{3} \mathrm{~A}$ in the cement pastes with $\mathrm{LiNO}_{3}$, which is visible in the form of a characteristic bulge, is moved significantly in time with the movement in time ranging from $7.5 \mathrm{~h}\left(100 \% \mathrm{LiNO}_{3}\right)$ to $8.5 \mathrm{~h}\left(200 \% \mathrm{LiNO}_{3}\right)$. Additionally, it needs to be noted that mutual movements of the energy transfer effect connected with the hydration of $\mathrm{C}_{3} \mathrm{~S}$ relative to the same energy transfer effect originating from the $\mathrm{C}_{3} \mathrm{~A}$ phase decrease with the increase of the amount of $\mathrm{LiNO}_{3}$ being introduced. 


\subsection{Phase composion}

The results of the X-ray analyses executed within the initial periods of hydration (up to 72h) confirm the acceleration of the hydration processes of the $\mathrm{C}_{3} \mathrm{~A}$ phase with the lithium additive present. Lithium nitrate increases the solubility of gypsum, leading to the decreases in the peak intensity, with the angle equal to $2 \theta=11.6^{\circ}$ (Fig. 2). At the same time, the intensity of the ettringite peak increase $\left(9.1^{\circ}\right.$ Theta). Gypsum originating peak was only found in the cement sample without the lithium additive after $12 \mathrm{~h}$.

Portlandite peaks, which are the evidence of the progress of the calcium silicates hydration also prove to be more intense in the pastes with the lithium additive. Additionally, with the increase of the amount of $\mathrm{LiNO}_{3}$ the hydration of the $\mathrm{C}_{3} \mathrm{~S}$ phase progresses as well, which has also been noticed by Bentz [16]. Lithium ions may play a role in the hydration processes similar to that of the remaining alkali ions. The acceleration of the hydration process of phase $\mathrm{C}_{3} \mathrm{~S}$ is probably the result of the nucleation processes occurring in the hydration products containing calcium, which occur faster as a result of the decrease in the solubility of calcium compounds in the pore solution. Moreover, as it is indicated by Kurdowski after Jawed and Skalny, all the salts causing oversaturation of a solution relative to scarcely soluble calcium compounds, contribute towards keeping the concentration of calcium low in the liquid phase, and therefore to increasing the solubility of the initial phase $\mathrm{C}_{3} \mathrm{~S}$ [17]. These statements are in accordance with the results of the X-ray analyses of the course of hydration processes. It needs to be remembered that the addition of an electrolyte to the cement paste is connected both with the cation and the anion impact on the electrical double layer. The ions which accelerate hydration, some of which are lithium ions and nitrate ions, cause the double layer to become thinner and lower the zeta potential, which facilitates the coagulation of the colloidal phase C-S-H [18].

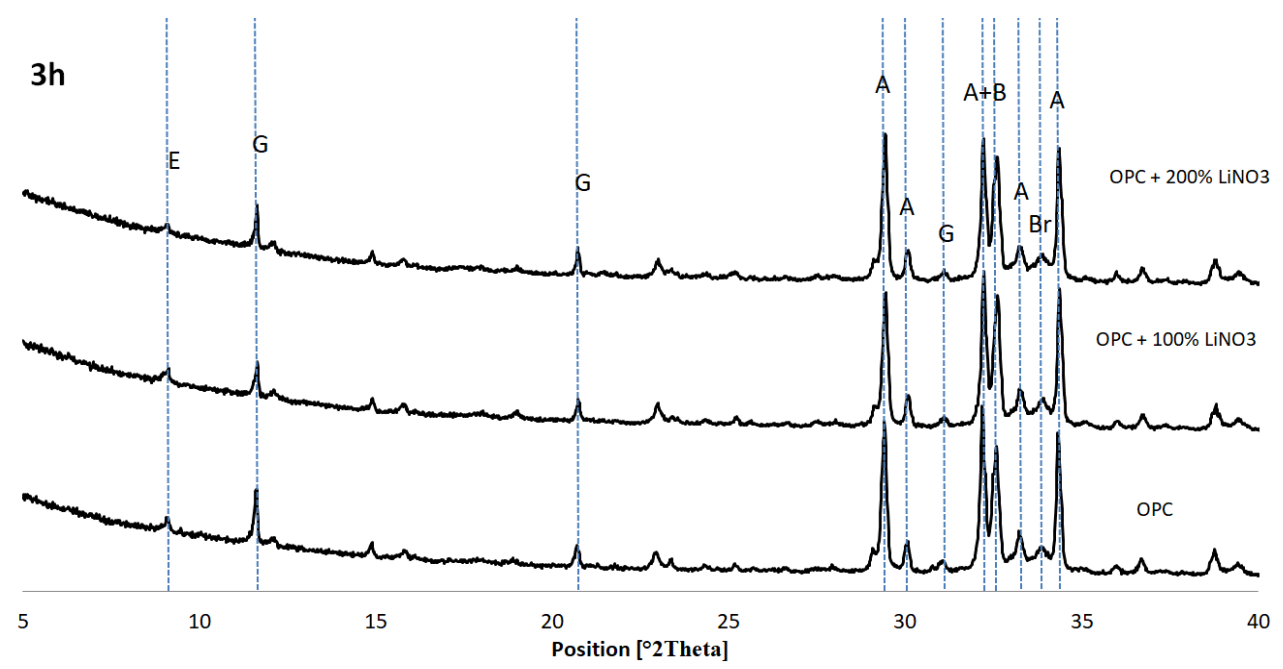

Fig. 2. X-ray patterns of Portland cement with $100 \%$ and $200 \%$ of the $\mathrm{LiNO}_{3}$, dosage, hydrating for 3 h. E - ettringite, G - gypsum, A - Alite, B - Belite, Br - Brownmillerite. 


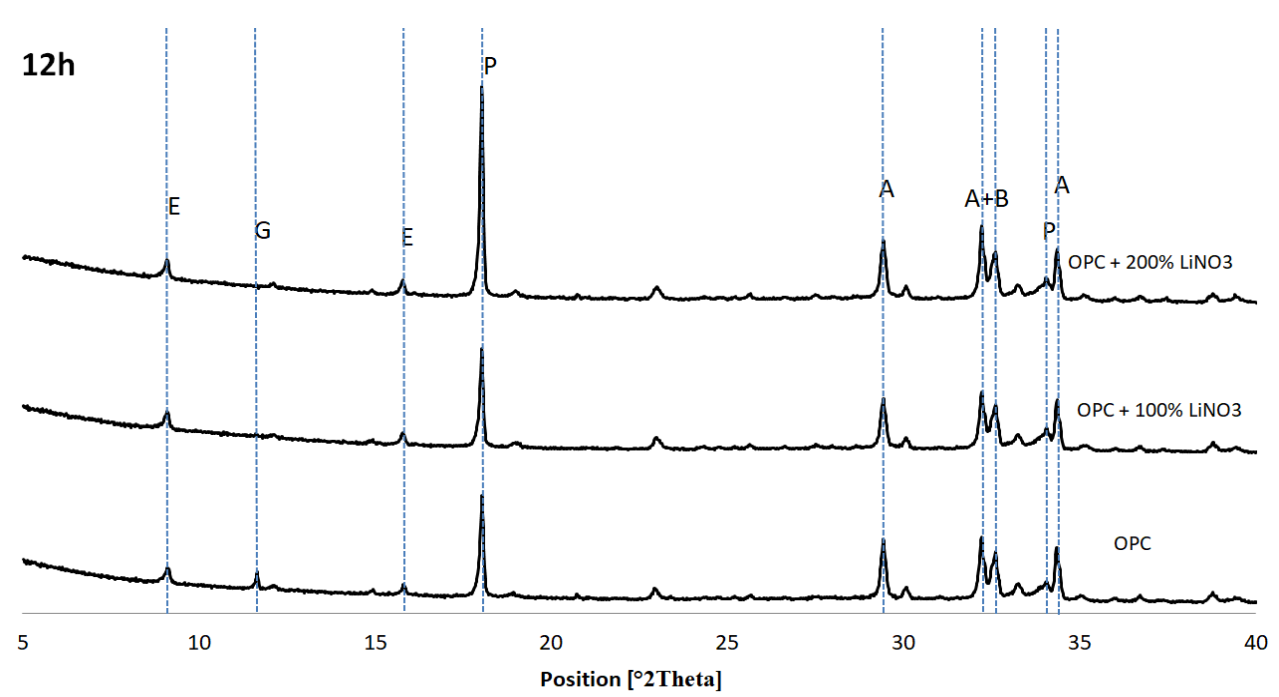

Fig. 3. X-ray patterns of Portland cement with $100 \%$ and $200 \%$ of the $\mathrm{LiNO}_{3}$, dosage, hydrating for 12 h. E - ettringite, G - gypsum, P - Portlandite, A - Alite, B - Belite.

After 24 hours of cement hydration, the amount of portlandite is also the greatest in the sample with the lithium additive, which is indicated by the increased intensity of peaks with 18.0 and $34.1^{\circ}$ Theta (Fig. 4). The results of the X-ray analyses are in good correlation with the results of the calorimetric analysis of the cement pastes. After $72 \mathrm{~h}$, with the increase of the amount of lithium nitrate, the intensity of the portlandite peak increases insignificantly, compared to the paste without the additive (Fig. 5).

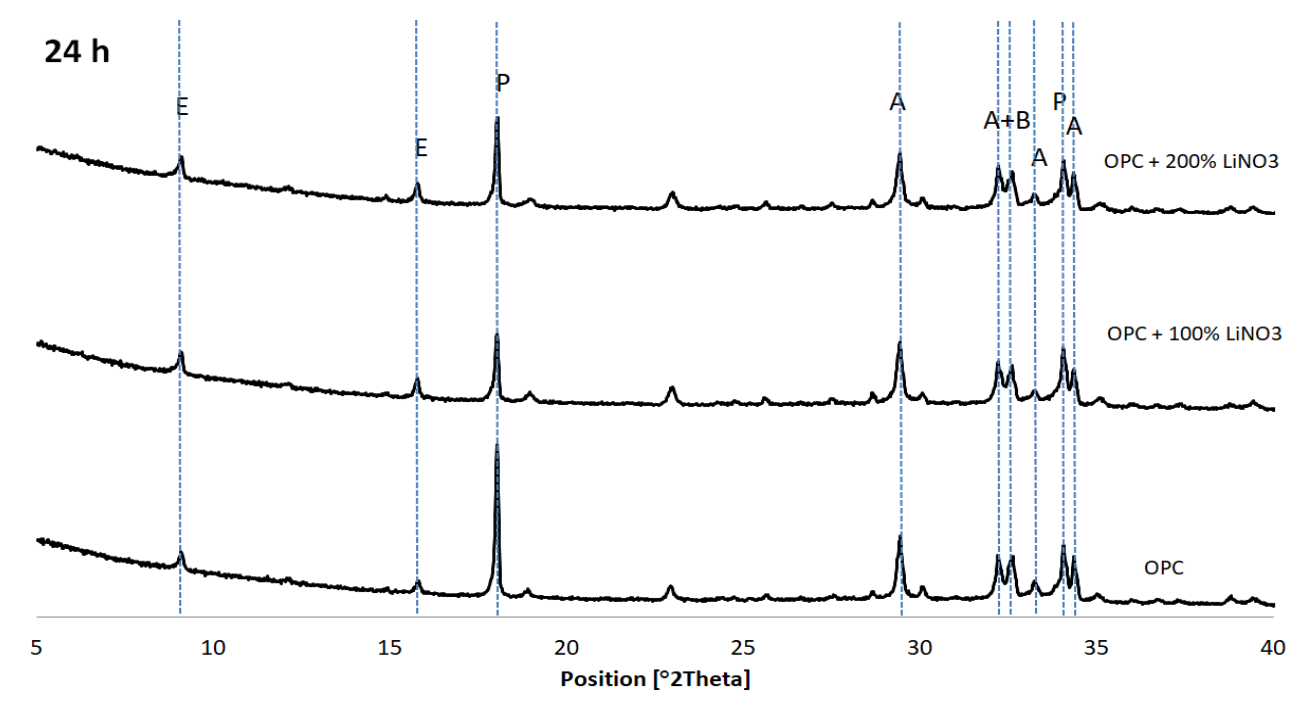

Fig. 4. X-ray patterns of Portland cement with $100 \%$ and $200 \%$ of the $\mathrm{LiNO}_{3}$, dosage, hydrating for 24 h. E - ettringite, G - gypsum, P - Portlandite, A - Alite, B - Belite. 


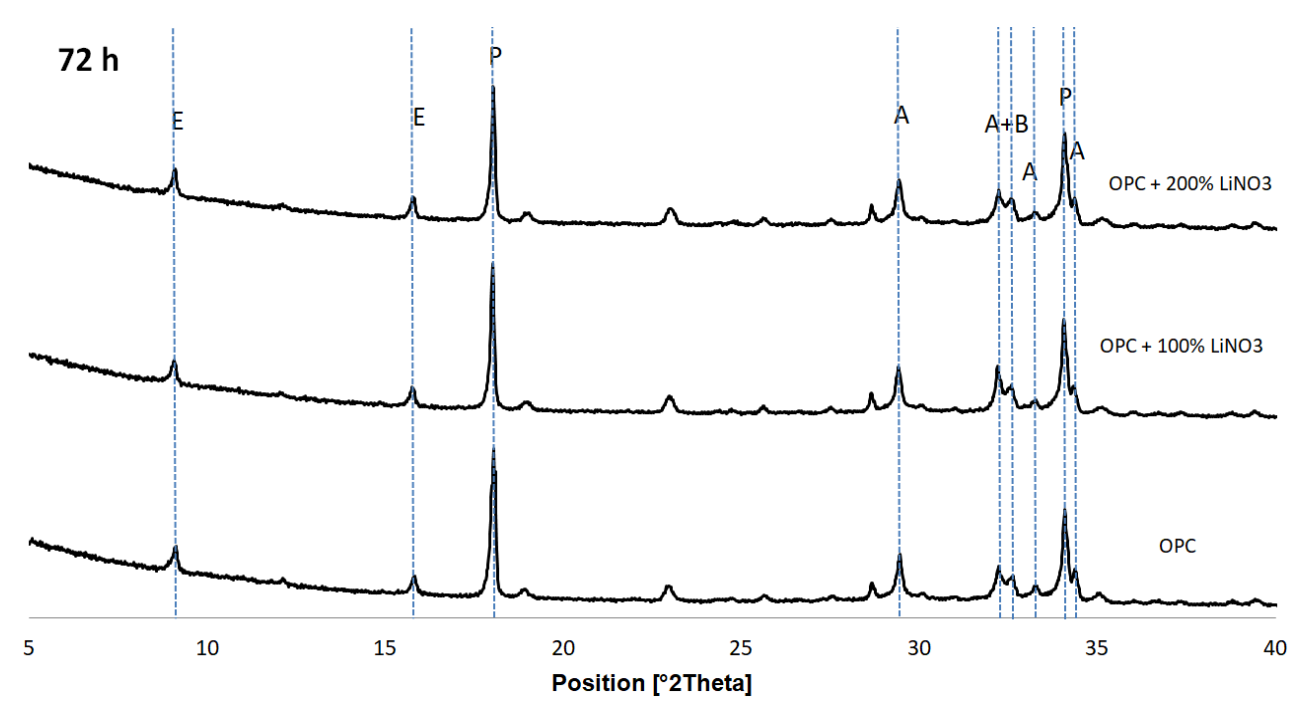

Fig. 5 X-ray patterns of Portland cement with $100 \%$ and $200 \%$ of the $\mathrm{LiNO}_{3}$ dosage, hydrating for 72h. E - ettringite, G - gypsum, P - Portlandite, A - Alite, B - Belite

\subsection{Setting time and compressive strength}

Figure 6 shows the test results for the setting time of cement pastes with different contents of lithium nitrate. At the same time, it was found that adding the lithium additive causes the decrease of the cement's water demand. Lithium nitrate causes the beginning of cement setting to shorten. The $\mathrm{LiNO}_{3}$ additive amounting to $100 \%$ and $200 \%$ causes the loss of plasticity time in the cement paste to accelerate by $9 \%$ and $15 \%$ accordingly. The completion of the setting of the pastes with a lithium additive is also shortened (by 35-50 minutes) relative to the sample without the lithium compound introduced.

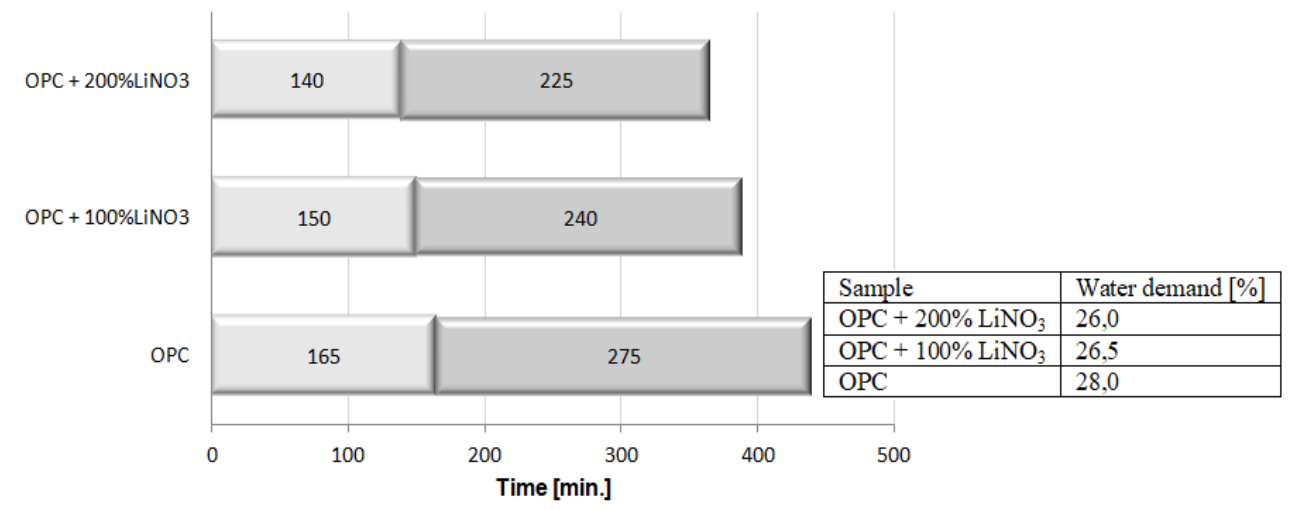

Fig. 6 The setting time and the water demand of the Portland cement with different amounts of the lithium nitrate additive

Figure 7 shows the test results of the compressive strength of cement mortars with different contents of lithium nitrate after 2, 7 and 28 days of hardening. 


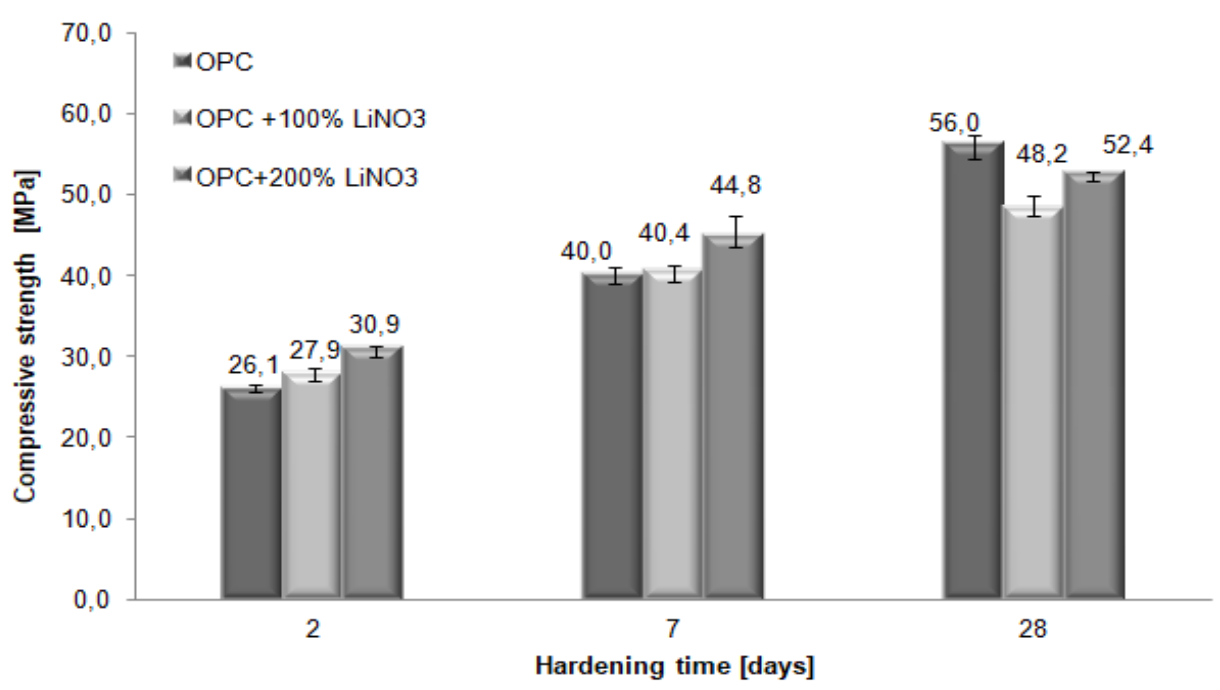

Fig. 7. Compressive strength of cement mortars with the $\mathrm{LiNO}_{3}$ additive.

Adding the lithium additive in the amount of $100 \%$ of the recommended dosage of $\mathrm{LiNO}_{3}$ causes the compressive strength to increase after 2 and 7 days of hardening. The greatest increase in the compressive strength was found in mortars with $200 \%$ of the recommended dosage of the chemical additive. The compressive strength of the mortars with the $\mathrm{LiNO}_{3}$ additive after 28 days of hardening is lowered. In the case being analysed by the author the compressive strength is lowered by $14 \%$ and $6 \%$ accordingly for the dosages of $100 \%$ and $200 \%$ of lithium nitrate.

\section{Conclusions}

The conducted tests have shown that lithium nitrate influences the hydration processes of the Portland cement. The calorimetric tests of the cement pastes with $100 \%$ and $200 \%$ of the recommended dosage of $\mathrm{LiNO}_{3}$, where the dosage of $100 \%$ corresponds to the molar ratio of $\mathrm{Li}$ to $[\mathrm{Na}+\mathrm{K}]=0.74$, and is used the most frequently to limit the alkali aggregate reactions, are evidence for the acceleration of the hydration of phases $\mathrm{C}_{3} \mathrm{~A}$ and $\mathrm{C}_{3} \mathrm{~S}$. The test results of the phase composition indicate more intense reflexes of ettringite in the samples with the lithium additive introduced and greater intensities of the portlandite peaks accordingly. It is possible that the acceleration in the $\mathrm{C}_{3} \mathrm{~S}$ hydration is a result of the decrease in the solubility of the products of hydration containing calcium, which accelerates the nucleation process, whereas quicker hydration of the $\mathrm{C}_{3} \mathrm{~A}$ is a result of the increase in the solubility of this phase influenced by the lithium compound. The beginning and the end of cement setting time are both shortened, however an insignificant interval increase was found between the beginning and the end, as more $\mathrm{LiNO}_{3}$ was introduced. Relative to the reference paste, the beginning of the setting is shortened by $9 \%-15 \%$, whereas the end is shortened by $13 \%-18 \%$. The acceleration of the beginning and the end of the cement setting for $100 \%$ and $200 \%$ of the recommended $\mathrm{LiNO}_{3}$ was also observed by Millard and Kurties, in particular in low-alkali cement $[3,14]$. For high-alkali cement the differences relative to the reference sample were slight. Lithium nitrate affects the mortar strengths. The test results remain in accordance with the pattern showing that setting and hardening accelerators at the same time cause a decrease in durability after 28 days. The tests performed by Wang, who analysed the effect of $\mathrm{LiOH}$ on the mechanical properties of mortars, indicate that a decrease in the durability of mortars with a lithium additive and a high-alkali cement and an increase in the durability of low- 
alkali mortars is possible [19]. Millard and Kurties also made note of the negative effect of bigger doses of lithium on compressive strength [3]. These findings are particularly crucial due to the necessity of increasing the amount of $\mathrm{LiNO}_{3}$ in order to protect reactive aggregate grains, advocated by many researchers.

\section{References}

1. T.E. Stanton, Proc. ASCE 66, 1781 (1940)

2. E.G. Swenson, ASTM Bull. 226, 48 (1957)

3. M.J. Millard, K.E. Kurtis, Cem. Concr. Res. 38, 500 (2008)

4. M. Thomas, Cem. Concr. Res. 41(12), 1224 (2011)

5. Z. Owsiak, P. Czapik, Cement Lime Concrete 3, 6 (2014)

6. Z. Owsiak, P. Czapik, Bull. Pol. Ac.: Tech. 63 (1), 4 (2015)

7. J. Zapała-Sławeta, J. Mater Struct. 50, 217 (2017)

8. W.J. McCoy, A.G. Caldwell, ACI Mat. J. 22(9), 693 (1951)

9. K.J. Folliard, M.D. Thomas, K.E. Kurtis, FHWA Report: FHWA-RD-03-047, July 2003

10. Z. Owsiak, J. Zapała-Sławeta, Cement Lime Concrete 20, 25 (2015)

11. J. Zapała-Sławeta, Z. Owsiak, Bull. Pol. Ac.:Tech. 65 (6), 773 (2017)

12. X. Feng, Effects and mechanism of lithium nitrate on controlling alkali-silica reaction, (PhD Thesis, University of New Brunswick, Canada, 2008)

13. Z. Owsiak, J. Zapała-Sławeta, Ceram.- Silik. 57 (2), 138 (2013)

14. M. Millard, K. Kurtis, Lithium Admixtures (LiNO ${ }_{3}$ ) And Properties of Early Age Concrete (An IPRF Research Report Innovative Pavement Research Foundation Airport Concrete Pavement Technology Program ,Skokie, USA, 2006)

15. $\mathrm{PN}-\mathrm{EN} 196-3$ (2006)

16. D.P. Bentz, ADV CEM RES 18, 65 (2006)

17. W. Kurdowski, The Chemistry of Cement and Concrete (SPC, Kraków, 2010)

18. R. Kondo, M. Daimon, E. Sakai, H. Oshiyama, J. Appl. Chem. Biotechnol. 27, 191 (1977)

19. W.Ch. Wang, Constr. Build. Mater. 50, 727 (2014) 